\title{
Manejo do nitrogênio para eficiência de uso por cultivares de feijoeiro em várzea tropical
}

\author{
Alberto Baêta dos Santos(1) e Nand Kumar Fageria(1) \\ (1)Embrapa Arroz e Feijão, Caixa Postal 179, CEP 75375-000 Santo Antônio de Goiás, GO. E-mail: baeta@cnpaf.embrapa.br, \\ fageria@cnpaf.embrapa.br
}

\begin{abstract}
Resumo - O objetivo deste trabalho foi avaliar a resposta e a eficiência do uso de N, por cultivares de feijoeiro, em função do manejo do fertilizante nitrogenado em solo de várzea. O delineamento experimental foi o inteiramente casualizado, com seis repetições, no esquema de parcelas divididas constituídas pelos manejos de N, e as subparcelas pelas cultivares. A aplicação de N no sulco de semeadura causou efeito salino do fertilizante, o que reduziu a população de feijoeiros. A incorporação de todo o $\mathrm{N}$ em sulcos distintos das linhas da semeadura, por ocasião dessa ou até 15 dias após a emergência, é mais eficaz no aumento da produtividade de grãos de feijão, do que a aplicação a lanço na superfície ou incorporada com grade antes da semeadura. A cultivar BRS Pontal foi a mais produtiva, o que é indicativo de alta adaptação ao ambiente de várzea tropical. Houve diversidade na eficiência de uso de $\mathrm{N}$ entre as cultivares de feijoeiro, e as de ciclo médio foram mais eficientes do que as precoces. A produtividade de grãos foi positivamente associada às eficiências agronômica, de recuperação e de utilização de N. A produtividade de grãos e a eficiência de uso de N pelas cultivares diferem conforme o manejo do fertilizante nitrogenado.
\end{abstract}

Termos para indexação: Phaseolus vulgaris, acumulação de nitrogênio, adubação nitrogenada, adubação de cobertura.

\section{Nitrogen fertilizer management for efficient use by dry bean in tropical lowland}

\begin{abstract}
The objective of this work was to evaluate the response and efficiency of $\mathrm{N}$ applied to bean cultivars in lowland soils. A completely randomized desing comprising six replicates, with split plots consisting of $\mathrm{N}$ management treatments, and the subplots consisting of cultivars, was used. Application of total $\mathrm{N}$ in furrow at sowing caused saline effect of fertilizer on seeds, and reduced the crop stand. Total $\mathrm{N}$ applied and incorporated in the furrow at sowing, as well as 15 days after emergence between rows, was more effective compared to fertilizer applied in broadcast or incorporated into the soil by ploughing before sowing, regarding grain yield. There was diversity among cultivars in relation to the efficiency of $\mathrm{N}$ use. Cultivar BRS Pontal was more productive, indicating high adaptability to tropical lowland environment. Nitrogen use efficiency was higher in medium growth cycle cultivars compared to early maturing cultivars. Grain yield was positively associated with agronomic efficiency, recovery and utilization efficiencies. Grain yield and $\mathrm{N}$ use efficiency by cultivars differ according to $\mathrm{N}$ fertilizer management.
\end{abstract}

Index terms: Phaseolus vulgaris, nitrogen accumulation, nitrogen fertilization, topdressing.

\section{Introdução}

O cultivo do feijoeiro no sistema de subirrigação, na entressafra do arroz irrigado, tem-se mostrado como uma alternativa viável para aumentar a produtividade de grãos em várzeas (Santos \& Silveira, 1996). O feijoeiro é uma planta bastante exigente em nutrientes e, em razão do ciclo curto, necessita da pronta disponibilidade dos nutrientes nos momentos de demanda (Silva \& Silveira, 2000).
Em relação aos demais nutrientes, o nitrogênio $(\mathrm{N})$ é absorvido em quantidades mais elevadas pelo feijoeiro (Oliveira et al., 1996). A demanda por $\mathrm{N}$ pelo feijoeiro em várzeas é maior do que nos sistemas tradicionais de cultivo em terras altas (Santos et al., 2003). Possivelmente, isso se deva à grande quantidade de resíduos deixados na superfície do solo pela cultura do arroz irrigado, que propiciam maior imobilização e menor disponibilidade do nutriente para a cultura. O N é responsável pelo incremento da área foliar da planta, o 
que aumenta a eficiência de intercepção da radiação solar, a taxa fotossintética e, conseqüentemente, a produtividade de grãos (Fageria \& Baligar, 2005). O uso da dose adequada de $\mathrm{N}$ evita o aumento excessivo da área foliar, que pode propiciar auto-sombreamento, o qual diminui a eficiência fotossintética e a transpiração.

Por ser o $\mathrm{N}$ um elemento que se perde facilmente por vários processos como volatilização, lixiviação e desnitrificação no sistema solo-planta (Fageria \& Baligar, 2005), o manejo adequado com o propósito de maximizar a eficiência de seu uso é altamente desejável. Para tanto, tem-se buscado reduzir sua perda no solo e melhorar sua absorção pelas plantas (Bredemeier \& Mundstock, 2000). Se não for adotado o manejo apropriado, pode ocorrer deficiência de $\mathrm{N}$, o que resulta em plantas com baixa fitomassa e senescência prematura, evidenciada pelo amarelecimento das folhas mais velhas. A eficiência de uso das fontes de $\mathrm{N}$ pelas culturas anuais como o feijoeiro é baixa, ao redor de $50 \%$, e uma das causas para esse baixo valor está relacionada à dose e à época de aplicação inadequadas (Fageria \& Baligar, 2005).

Cerca de $50 \%$ do $\mathrm{N}$ total absorvido é exportado pelos grãos, e o restante permanece no solo, na forma de resíduos culturais (Oliveira et al., 1996; Fageria \& Baligar, 2005). A baixa recuperação de $\mathrm{N}$ é responsável não somente pelo maior custo de produção, mas também pela poluição ambiental (Fageria \& Baligar, 2005). A melhoria da eficiência de uso de $\mathrm{N}$ é desejável para aumentar a produtividade, reduzir os custos de produção e manter a qualidade ambiental.

A maioria dos estudos sobre métodos e épocas de adubação nitrogenada para o feijoeiro refere-se ao cultivo em terras altas, onde se recomenda uma ou duas aplicações parceladas a lanço (Oliveira et al., 1996). Santos \& Silva (2002) relatam que, devido ao rápido crescimento do feijoeiro em várzeas tropicais, a incorporação de $\mathrm{N}$ deve ser feita antes do fechamento das entrelinhas. Santos et al. (2003) verificaram que o feijoeiro apresentou melhor resposta à aplicação de parte do $\mathrm{N}$ incorporada ao solo, do que a aplicação a lanço na superfície.

Os sistemas agrícolas influenciam as respostas do feijoeiro à adubação nitrogenada (Silva \& Silveira, 2000). Assim, o cultivo dessa leguminosa em várzeas necessita de ajustes em seu manejo. A eficiência de recuperação de $\mathrm{N}$ pelo feijoeiro pode ser aumentada com a adoção de manejo apropriado, como o uso de dose e época de aplicação adequadas às necessidades da cultura. Com isso, a estratégia de adubação de $\mathrm{N}$ deve ter como objetivo melhorar a sincronia entre a época de aplicação e a época de maior demanda pela planta, de forma a maximizar a absorção do nutriente e a produtividade de grãos.

O objetivo deste trabalho foi avaliar a resposta e a eficiência do uso de $\mathrm{N}$, por cultivares de feijoeiro, em função do manejo do fertilizante nitrogenado em várzea.

\section{Material e Métodos}

O experimento foi conduzido de junho a setembro de 2004 e 2005, na Fazenda Xavante, no Município de Dueré, TO, na entressafra do arroz irrigado, em solo de várzea Gleissolo Háplico Ta distrófico, textura franco argilo arenosa.

As análises químicas e granulométricas das amostras de solo, coletadas no início do estudo nas camadas de $0-0,10 \mathrm{~m}$ e de $0,10-0,20 \mathrm{~m}$ de profundidade, apresentaram, respectivamente: 6,5 e 6,2 de $\mathrm{pH}$ em água (1:2,5); 4,3 e 2,9 cmol $_{\mathrm{c}} \mathrm{kg}^{-1} \mathrm{de} \mathrm{Ca}^{2+} ; 2,2$ e 1 cmol $_{\mathrm{c}} \mathrm{kg}^{-1}$ de $\mathrm{Mg}^{2+} ; 38,7$ e 22,6 $\mathrm{mg} \mathrm{kg}^{-1}$ de P; 92 e $41 \mathrm{mg} \mathrm{kg}^{-1}$ de $\mathrm{K}^{+} ; 1,2$ e $0,7 \mathrm{mg} \mathrm{kg}^{-1}$ de Cu; 3,4 e $2 \mathrm{mg} \mathrm{kg}^{-1} \mathrm{de} \mathrm{Zn} ; 55$ e $49 \mathrm{mg} \mathrm{kg}^{-1}$ de Fe; 11 e $6 \mathrm{mg} \mathrm{kg}^{-1}$ de Mn; 32 e $29 \mathrm{~g} \mathrm{~kg}^{-1} \mathrm{de}$ MO; 267 e $247 \mathrm{~g} \mathrm{~kg}^{-1}$ de argila; 200 e $160 \mathrm{~g} \mathrm{~kg}^{-1}$ de silte; 533 e $593 \mathrm{~g} \mathrm{~kg}^{-1}$ de areia.

Em 2004, foram avaliados seis manejos de N: M1, sem $\mathrm{N}$; M2, todo o $\mathrm{N}$ incorporado ao solo nas entrelinhas, aos 15 dias após a emergência (DAE); M3, todo o N aplicado a lanço em cobertura, aos 15 DAE; M4, todo o $\mathrm{N}$ incorporado com grade antes da semeadura; M5, metade do N aplicado no sulco de semeadura, e o restante incorporado ao solo nas entrelinhas, aos 15 DAE; M6, todo o N aplicado no sulco de semeadura. Foram avaliadas seis cultivares de feijoeiro, com as seguintes características de grupo comercial e hábito de crescimento: BRS Grafite e BRS Valente - Preto, ereto (II); BRS Pontal e Pérola - Carioca, semi-ereto (II/III); BRS Radiante e Jalo Precoce - Manteigão/ Rajado, ereto (I).

Em 2005, avaliaram-se sete manejos de N: M1, sem $\mathrm{N}$; M2, todo o $\mathrm{N}$ incorporado ao solo nas entrelinhas, aos 15 DAE; M3, todo o $\mathrm{N}$ a lanço em cobertura, aos 15 DAE; $\mathrm{M} 4$, todo o $\mathrm{N}$ incorporado ao solo no sentido transversal às linhas de semeadura; M5, todo o N incorporado com grade antes da semeadura; M6, metade do $\mathrm{N}$ aplicado no sulco de semeadura, e o restante incorporado ao solo nas entrelinhas, aos $15 \mathrm{DAE}$; $\mathrm{M} 7$, todo o $\mathrm{N}$ incorporado ao solo nas entrelinhas, por ocasião de semeadura. Foram utilizadas as mesmas cultivares de 2004. 
Nos dois anos, a adubação nitrogenada consistiu da aplicação de $90 \mathrm{~kg} \mathrm{ha}^{-1}$ de $\mathrm{N}$, na forma de uréia, e as adubações fosfatada e potássica foram de $100 \mathrm{~kg} \mathrm{ha}^{-1}$ de $\mathrm{P}_{2} \mathrm{O}_{5}$ e de $100 \mathrm{~kg} \mathrm{ha}^{-1}$ de $\mathrm{K}_{2} \mathrm{O}$, tendo-se empregado o formulado 0-20-20. Após a semeadura, passou-se rolo compactador em toda a área, a fim de se favorecer a redistribuição da água até a superfície do solo (Aidar et al., 2002), durante a subirrigação - método no qual a água é aplicada diretamente sob a superfície do solo, por meio da manutenção e controle do lençol freático à profundidade preestabelecida (Bernardo, 2005).

$\mathrm{O}$ delineamento experimental foi o inteiramente casualizado, com seis repetições, no esquema de parcelas divididas constituídas pelos manejos de N, e as subparcelas pelas cultivares, com seis linhas de $50 \mathrm{~m}$ de comprimento, espaçadas em $0,45 \mathrm{~m}$.

Em 2005, para a determinação do acúmulo de matéria seca da parte aérea (MSPA) e de N, realizaram-se quatro amostragens de plantas, em $0,50 \mathrm{~m}$ da linha de semeadura, aos 17, 28, 42, 62 e 67 DAE, nas cultivares precoces BRS Radiante e Jalo Precoce, e cinco amostragens em duas cultivares de ciclo médio, a BRS Grafite e a BRS Pontal. O N da parte aérea e dos grãos foi determinado pelo método micro-Kjeldahl. As curvas de massa da MSPA e de acumulação de $\mathrm{N}$ na parte aérea foram ajustadas por equações de regressão, tendo-se testado modelos lineares e quadráticos.

Por ocasião da colheita, foram determinados os números de plantas na área útil, vagens por planta e grãos por vagem, a massa de 100 grãos, a produtividade de grãos (ajustada em 13\% de umidade) e a produtividade biológica. Foram calculadas as eficiências agronômica (EA), fisiológica (EF), agrofisiológica (EAF), de recuperação (ER) e de utilização (EU), conforme Fageria \& Stone (2003) e Fageria \& Baligar (2005).

Os dados obtidos foram submetidos à análise de variância, e as médias foram comparadas pelo teste de Scott-Knott.

\section{Resultados e Discussão}

Em 2004, a aplicação de $90 \mathrm{~kg} \mathrm{ha}^{-1}$ de $\mathrm{N}$, incorporados ao sulco de semeadura (M6), causou severo dano à germinação das sementes, com comprometimento da emergência das plântulas de feijoeiro, pelo efeito salino do fertilizante sobre a semente. Diversos estudos mostraram que a população de feijoeiro é afetada pela aplicação do fertilizante nitrogenado ao sulco de semeadura. Silva et al. (2002) verificaram que a aplicação de dose de $\mathrm{N}$ acima de $80 \mathrm{~kg} \mathrm{ha}^{-1}$, na linha de semeadura, não resultou em aumento da produtividade de feijão em razão da diminuição do número de plantas. Kluthcouski et al. (2004) também verificaram efeito salino da uréia aplicada na linha de semeadura, o que diminuiu substancialmente a população de feijoeiros, e relataram que os fertilizantes minerais devem ser adequadamente posicionados, para se evitarem esses efeitos danosos. Portanto, o manejo M6 não foi considerado, e a análise do experimento foi realizada apenas com os demais tratamentos. As adubações nitrogenadas na semeadura, que tivessem todo o $\mathrm{N}$ incorporado com grade (M4) ou metade aplicada no sulco de semeadura (M5), também afetaram o estande de plantas (Tabela 1).

Quanto à produtividade de grãos e seus componentes, e quanto à eficiência agronômica, as cultivares responderam diferentemente aos manejos de $\mathrm{N}$, exceto a cultivar Pérola. De modo geral, a testemunha sem $\mathrm{N}$ (M1) proporcionou os menores valores de produtividade de grãos e de seus componentes, em todas as cultivares. As maiores respostas das cultivares ocorreram quando todo o $\mathrm{N}$ foi incorporado ao solo nas entrelinhas, aos $15 \mathrm{DAE}$ (M2), ou aplicado a lanço em cobertura (M3). Esses tratamentos também resultaram nas maiores EA de $\mathrm{N}$ (Tabela 1), como no caso da cultivar BRS Grafite, que produziu até $18 \mathrm{~kg}$ de grãos por quilograma de $\mathrm{N}$ aplicado.

Em 2005, os melhores ajustes da massa de MSPA e da acumulação de $\mathrm{N}$ na parte aérea, em função do tempo, foram obtidos por equações exponenciais. De modo geral, em relação às mudanças ontogenéticas, suas evoluções mostraram que as diferenças entre os manejos de $\mathrm{N}$ aumentaram com o desenvolvimento das plantas de feijoeiro (Figura 1). Maiores valores de fitomassa e de acumulação de $\mathrm{N}$ ocorreram com as cultivares de ciclo médio, BRS Pontal e BRS Grafite, que também apresentaram maiores diferenças nesses valores em conseqüência do manejo de $\mathrm{N}$. A maior produtividade biológica das cultivares de ciclo médio, em relação às precoces, pode estar associada à maior duração do período vegetativo. Há tendência de genótipos de ciclo médio apresentarem, sob condições similares, maior produtividade biológica.

As cultivares apresentaram três estádios de crescimento: inicialmente, o crescimento foi lento, e a acumulação de matéria seca até cerca de 25 DAE foi pequena; a partir daí, o crescimento foi acelerado, até atingir os maiores valores, quando, então, a massa de MSPA começou a diminuir, e o crescimento foi 
decrescendo em decorrência da senescência. As maiores massas de MSPA nas cultivares precoces ocorreram mais cedo, ao redor de $50 \mathrm{DAE}$, enquanto nas cultivares de ciclo médio isso se deu aos 65 DAE. Entre as precoces, a máxima massa de MSPA foi obtida com a cultivar BRS Radiante $\left(322 \mathrm{~g} \mathrm{~m}^{-2}\right)$, aos 50 DAE.
Entre as de ciclo médio, a máxima massa de MSPA foi obtida pela cultivar BRS Grafite, com $498 \mathrm{~g} \mathrm{~m}^{-2}$, aos 65 DAE. Decréscimos da massa de MSPA, na colheita, podem ser atribuídos à translocação dos produtos fotossintéticos para os grãos, no intervalo da floração à colheita (Fageria \& Baligar, 2005).

Tabela 1. Efeitos do manejo de nitrogênio, na produtividade de grãos e seus componentes, e na eficiência agronômica (EA) de cultivares de feijoeiro em várzea, em 2004(1).

\begin{tabular}{|c|c|c|c|c|c|c|}
\hline $\begin{array}{l}\text { Manejo } \\
\text { de } N^{(2)}\end{array}$ & $\begin{array}{c}\text { Plantas } \\
\left(\mathrm{n}^{\mathrm{o}} \text { por } \mathrm{m}^{2}\right)\end{array}$ & $\begin{array}{c}\text { Vagens } \\
\left(\mathrm{n}^{\mathrm{o}} \text { por planta }\right) \\
\end{array}$ & $\begin{array}{c}\text { Grãos } \\
\text { (n } \mathrm{n}^{\mathrm{o}} \text { por vagem) }\end{array}$ & $\begin{array}{c}\text { Massa de } \\
100 \text { grãos }(\mathrm{g})\end{array}$ & $\begin{array}{c}\text { Produtividade de grãos } \\
\left(\mathrm{kg} \mathrm{ha}^{-1}\right)\end{array}$ & $\begin{array}{c}\mathrm{EA} \\
\left(\mathrm{kg} \mathrm{kg}^{-1}\right) \\
\end{array}$ \\
\hline \multicolumn{7}{|c|}{ BRS Pontal } \\
\hline M1 & $24,5 \mathrm{a}$ & $4,3 \mathrm{c}$ & $4,9 \mathrm{a}$ & $24,0 \mathrm{~b}$ & $1.245 b$ & - \\
\hline M2 & $26,2 \mathrm{a}$ & $7,4 b$ & $5,0 \mathrm{a}$ & $27,1 \mathrm{a}$ & $2.599 \mathrm{a}$ & $15 \mathrm{a}$ \\
\hline M3 & $21,7 b$ & $7,9 b$ & $5,2 \mathrm{a}$ & $26,4 a$ & $2.355 \mathrm{a}$ & $12 \mathrm{a}$ \\
\hline M4 & $15,9 \mathrm{c}$ & $8,7 \mathrm{~b}$ & $4,9 a$ & $25,5 \mathrm{a}$ & $1.690 \mathrm{~b}$ & $5 b$ \\
\hline M5 & $10,9 \mathrm{~d}$ & $19,1 \mathrm{a}$ & $5,0 \mathrm{a}$ & $26,1 \mathrm{a}$ & $2.516 \mathrm{a}$ & $14 \mathrm{a}$ \\
\hline Média & 19,8 & 9,5 & 5,0 & 25,8 & 2.081 & 12 \\
\hline \multicolumn{7}{|c|}{ Pérola } \\
\hline M1 & $17,7 \mathrm{c}$ & $9,4 \mathrm{~b}$ & $4,1 \mathrm{a}$ & $28,5 \mathrm{a}$ & $1.890 \mathrm{a}$ & - \\
\hline M2 & $24,2 \mathrm{a}$ & $7,6 b$ & $4,1 \mathrm{a}$ & $28,4 a$ & $2.126 \mathrm{a}$ & $3 a$ \\
\hline M3 & $19,8 b$ & $8,6 b$ & $4,2 \mathrm{a}$ & $28,9 a$ & $2.070 \mathrm{a}$ & $2 a$ \\
\hline M4 & $15,3 c$ & $10,2 b$ & $4,0 \mathrm{a}$ & $28,3 a$ & $1.740 \mathrm{a}$ & - \\
\hline M5 & $12,6 \mathrm{~d}$ & $13,1 \mathrm{a}$ & $4,0 \mathrm{a}$ & $29,6 \mathrm{a}$ & $1.926 \mathrm{a}$ & - \\
\hline Média & 17,9 & 9,8 & 4,1 & 28,7 & 1.950 & 1 \\
\hline \multicolumn{7}{|c|}{ BRS Valente } \\
\hline M1 & $18,0 \mathrm{a}$ & $5,1 d$ & $4,1 b$ & $19,5 \mathrm{~d}$ & $679 c$ & - \\
\hline M2 & $19,0 \mathrm{a}$ & $11,7 \mathrm{c}$ & $4,1 b$ & $24,7 \mathrm{a}$ & $2.244 \mathrm{a}$ & $17 \mathrm{a}$ \\
\hline M3 & $11,9 b$ & $16,6 \mathrm{a}$ & $4,5 \mathrm{a}$ & $24,2 \mathrm{a}$ & $2.144 \mathrm{a}$ & $16 \mathrm{a}$ \\
\hline M4 & $8,1 \mathrm{c}$ & $11,9 \mathrm{c}$ & $3,9 \mathrm{~b}$ & $22,3 c$ & $790 \mathrm{c}$ & $1 \mathrm{c}$ \\
\hline M5 & $11,9 \mathrm{~b}$ & $14,1 \mathrm{~b}$ & $4,2 b$ & $23,4 b$ & $1.617 \mathrm{~b}$ & $10 \mathrm{~b}$ \\
\hline Média & 13,8 & 11,9 & 4,2 & 22,8 & 1.495 & 11 \\
\hline \multicolumn{7}{|c|}{ BRS Grafite } \\
\hline M1 & $31,6 a$ & $3,0 \mathrm{c}$ & $3,7 \mathrm{~d}$ & $22,0 \mathrm{c}$ & $765 d$ & - \\
\hline M2 & $31,9 \mathrm{a}$ & $6,3 b$ & $4,2 \mathrm{c}$ & $27,5 \mathrm{a}$ & $2.335 \mathrm{a}$ & $18 \mathrm{a}$ \\
\hline M3 & $27,1 b$ & $7,0 \mathrm{~b}$ & $4,8 \mathrm{a}$ & $26,4 b$ & $2.415 \mathrm{a}$ & $18 \mathrm{a}$ \\
\hline M4 & $21,1 \mathrm{c}$ & $7,5 b$ & $4,2 \mathrm{c}$ & $25,7 b$ & $1.673 \mathrm{c}$ & $10 \mathrm{c}$ \\
\hline M5 & $17,1 \mathrm{~d}$ & $10,7 \mathrm{a}$ & $4,4 \mathrm{~b}$ & $26,0 \mathrm{~b}$ & $1.995 \mathrm{~b}$ & $14 \mathrm{~b}$ \\
\hline Média & 25,7 & 6,9 & 4,3 & 25,5 & 1.837 & 15 \\
\hline \multicolumn{7}{|c|}{ BRS Radiante } \\
\hline M1 & $20,3 a$ & $5,0 \mathrm{c}$ & $2,7 b$ & $29,4 d$ & $788 d$ & - \\
\hline M2 & $18,7 \mathrm{a}$ & $9,8 \mathrm{~b}$ & $3,3 a$ & $40,1 \mathrm{a}$ & $2.355 \mathrm{a}$ & $17 \mathrm{a}$ \\
\hline M3 & $15,6 b$ & $10,8 b$ & $3,2 \mathrm{a}$ & $38,6 b$ & $2.016 \mathrm{~b}$ & $14 \mathrm{~b}$ \\
\hline M4 & $12,1 \mathrm{c}$ & $9,5 b$ & $3,0 \mathrm{a}$ & $31,7 \mathrm{c}$ & $1.110 \mathrm{c}$ & $4 c$ \\
\hline M5 & $10,1 \mathrm{c}$ & $17,0 \mathrm{a}$ & $3,0 \mathrm{a}$ & $39,3 \mathrm{~b}$ & $2.001 \mathrm{~b}$ & $14 \mathrm{~b}$ \\
\hline Média & 15,4 & 10,4 & 3,0 & 35,8 & 1.654 & 12 \\
\hline \multicolumn{7}{|c|}{ Jalo Precoce } \\
\hline M1 & $22,3 a$ & $4,3 d$ & $2,9 b$ & $28,9 c$ & $807 \mathrm{c}$ & - \\
\hline M2 & $22,8 \mathrm{a}$ & $7,0 \mathrm{c}$ & $3,8 \mathrm{a}$ & $36,9 a$ & $2.191 \mathrm{a}$ & $15 \mathrm{a}$ \\
\hline M3 & $17,8 \mathrm{~b}$ & $8,7 b$ & $3,7 \mathrm{a}$ & $34,5 b$ & $1.950 \mathrm{a}$ & $13 a$ \\
\hline M4 & $10,2 \mathrm{c}$ & $8,7 \mathrm{~b}$ & $3,5 \mathrm{a}$ & $29,6 c$ & $854 c$ & $1 \mathrm{c}$ \\
\hline M5 & $12,2 \mathrm{c}$ & $11,4 \mathrm{a}$ & $3,8 \mathrm{a}$ & $35,6 \mathrm{~b}$ & $1.643 \mathrm{~b}$ & $9 \mathrm{~b}$ \\
\hline Média & 17,0 & 8,0 & 3,5 & 33,1 & 1.489 & 10 \\
\hline CV (\%) & 15,8 & 20,4 & 6,3 & 3,4 & 14,5 & 30,3 \\
\hline
\end{tabular}


O padrão de acumulação de nutrientes nas culturas seguiu a acumulação de MSPA. O acúmulo máximo de $\mathrm{N}$ não diferiu entre as cultivares precoces e foi estimado
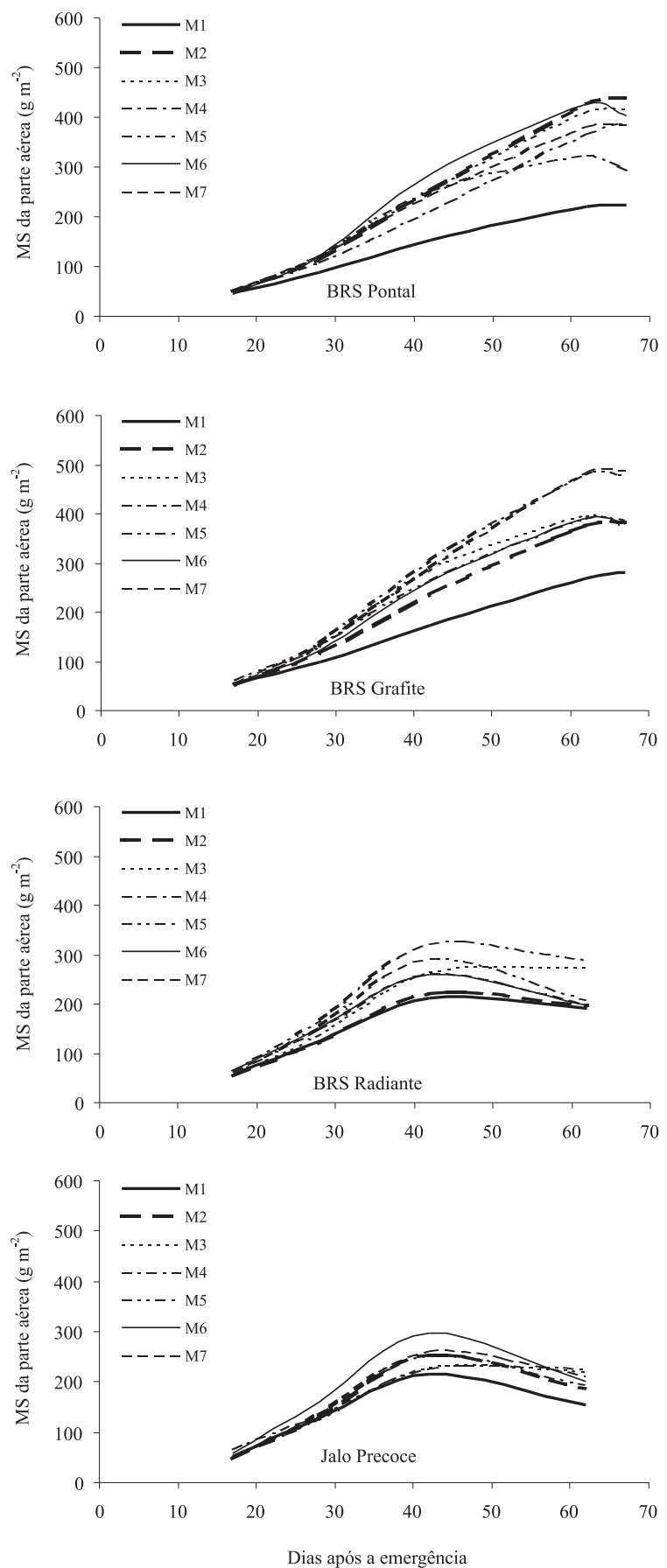

em $70 \mathrm{~kg} \mathrm{ha}^{-1}$, aos 38 DAE, com a cultivar Jalo Precoce, ao passo que nas de ciclo médio o máximo acúmulo de $\mathrm{N}$ foi de $96 \mathrm{~kg} \mathrm{ha}^{-1}$, aos $49 \mathrm{DAE}$, obtido com a cultivar
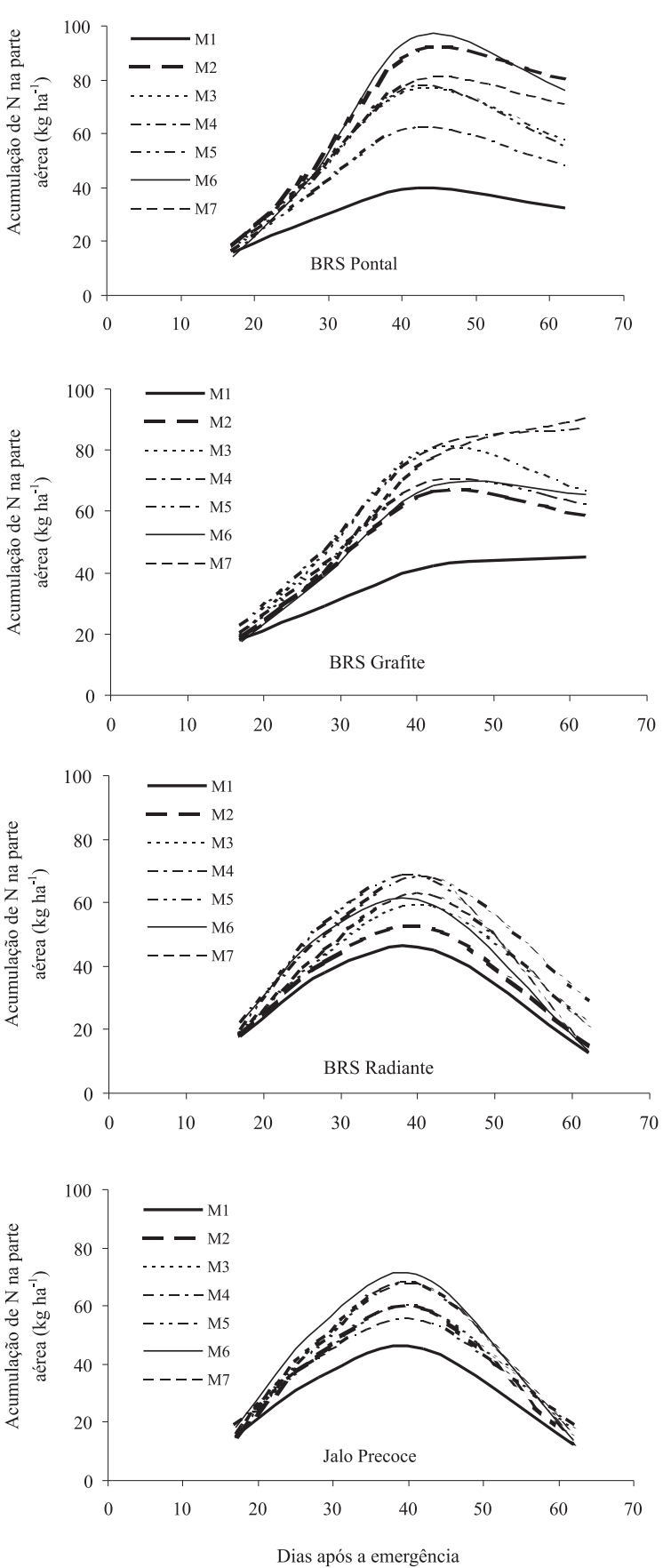

Figura 1. Evolução da massa da matéria seca da parte aérea e da acumulação de nitrogênio, afetadas pelo manejo de nitrogênio, em cultivares de feijoeiro em várzea, em 2005. M1, sem N; M2, todo o N incorporado ao solo nas entrelinhas, aos 15 DAE; M3, todo o nitrogênio a lanço, em cobertura, aos 15 DAE; M4, todo o nitrogênio incorporado ao solo no sentido transversal às linhas de semeadura; M5, todo o nitrogênio incorporado com grade antes da semeadura; M6, metade do nitrogênio aplicado no sulco de semeadura, e o restante incorporado ao solo nas entrelinhas, aos 15 DAE; M7, todo o nitrogênio aplicado ao solo nas entrelinhas, por ocasião da semeadura. 
BRS Pontal. A partir daí, a concentração de N na parte aérea decresceu com a idade das plantas. Isso era esperado, porque com o aumento da idade das plantas, mais matéria seca foi produzida, e isto diluiu a concentração de N.

Quanto aos acúmulos de MSPA e de N, na parte aérea, aos $17 \mathrm{DAE}$, houve efeito significativo apenas de cultivar, tendo a BRS Radiante apresentado maior massa de MSPA e, juntamente com a cultivar BRS Grafite, maior acúmulo de $\mathrm{N}$ que as demais (Tabela 2).

No início do florescimento das cultivares precoces, aos 28 DAE, houve efeito de cultivar e de manejo de $\mathrm{N}$ sobre a massa de MSPA (Tabela 2), enquanto a acumulação de $\mathrm{N}$ foi afetada pela interação entre cultivar e manejo do fertilizante (Tabela 3). No florescimento, as maiores fitomassas (Tabela 2) foram obtidas pelas cultivares precoces, e as menores pela testemunha (M1). As menores quantidades de $\mathrm{N}$ foram acumuladas nesse manejo em todas as cultivares, bem como no M4, na cultivar BRS Pontal, e também no M3, na cultivar BRS Radiante (Tabela 3). Isso mostra que até esse estádio essas formas de fornecimento do fertilizante nitrogenado propiciaram menor absorção de $\mathrm{N}$ pelas plantas de feijoeiro.
Aos 42 DAE, início do florescimento das cultivares de ciclo médio, as cultivares influenciaram significativamente apenas a massa de MSPA, enquanto os manejos de $\mathrm{N}$ influenciaram a massa de MSPA e o acúmulo de N (Tabela 2). Nessa terceira amostragem, a cultivar BRS Radiante, de porte ereto e hábito de crescimento do tipo I, também apresentou maior fitomassa que as demais, enquanto o tratamento sem $\mathrm{N}$ (M1) foi o menos produtivo e acumulou menos $\mathrm{N}$ na parte aérea.

Houve efeito da interação entre cultivar e manejo de $\mathrm{N}$, sobre a massa de MSPA e o acúmulo de $\mathrm{N}$, aos 62 DAE (Tabela 3). Nessa ocasião, as cultivares precoces, BRS Radiante e Jalo Precoce, já tinham completado o ciclo, e o manejo de $\mathrm{N}$ não afetou essas observações. O tratamento sem N (M1) apresentou o menor valor de MSPA e acumulou menos $\mathrm{N}$ nas cultivares de ciclo médio.

Aos 67 DAE, a massa de MSPA foi afetada pela cultivar e pelo manejo de $\mathrm{N}$ (Tabela 2), enquanto a acumulação de $\mathrm{N}$ foi influenciada pela interação entre esses fatores (Tabela 3). A cultivar BRS Grafite apresentou maior massa de MSPA do que a BRS Pontal, que acumulou menos $\mathrm{N}$ na incorporação do fertilizante com grade (M5) e na testemunha (M1). A maior

Tabela 2. Efeitos do manejo de nitrogênio e de cultivar, na massa da matéria seca da parte aérea (MSPA) e na acumulação de nitrogênio, no feijoeiro em várzea, em $2005^{(1)}$.

\begin{tabular}{|c|c|c|c|c|c|c|c|}
\hline $\begin{array}{c}\begin{array}{c}\text { Manejo } \\
\text { de } \\
\mathrm{N} \text { e cultivares }\end{array} \\
\end{array}$ & $\begin{array}{c}\text { MSPA } \\
17 \text { DAE } \\
\left(\mathrm{g} \mathrm{m}^{-2}\right)\end{array}$ & $\begin{array}{c}\text { Acumulação de } \mathrm{N} \\
\begin{array}{c}17 \text { DAE } \\
\left(\mathrm{kg} \mathrm{ha}^{-1}\right)\end{array}\end{array}$ & $\begin{array}{c}\text { MSPA } \\
28 \mathrm{DAE} \\
\left(\mathrm{g} \mathrm{m}^{-2}\right)\end{array}$ & $\begin{array}{c}\text { MSPA } \\
42 \text { DAE } \\
\left(\mathrm{g} \mathrm{m}^{-2}\right)\end{array}$ & $\begin{array}{c}\text { Acumulação de } \mathrm{N} \\
42 \text { DAE } \\
\left(\mathrm{kg} \mathrm{ha}^{-1}\right)\end{array}$ & $\begin{array}{l}\text { MSPA } \\
67 \text { DAE } \\
\left(\mathrm{g} \mathrm{m}^{-2}\right) \\
\end{array}$ & $\begin{array}{c}\text { Acumulação de } \\
\mathrm{N} \text { nos grãos } \\
\left(\mathrm{kg} \mathrm{ha}^{-1}\right)\end{array}$ \\
\hline \multicolumn{8}{|l|}{ Manejo de $\mathrm{N}^{(2)}$} \\
\hline M1 & $56 a$ & $19 \mathrm{a}$ & $99 b$ & $196 \mathrm{c}$ & $49 b$ & $213 b$ & $41 d$ \\
\hline M2 & $51 \mathrm{a}$ & $19 \mathrm{a}$ & $119 a$ & $232 b$ & $64 a$ & $333 a$ & $86 \mathrm{~b}$ \\
\hline M3 & $56 a$ & $21 \mathrm{a}$ & $119 a$ & $258 \mathrm{a}$ & $71 \mathrm{a}$ & $310 \mathrm{a}$ & $73 c$ \\
\hline M4 & $61 \mathrm{a}$ & $21 \mathrm{a}$ & $140 \mathrm{a}$ & $250 \mathrm{a}$ & $64 \mathrm{a}$ & $347 \mathrm{a}$ & $93 a$ \\
\hline M5 & $56 \mathrm{a}$ & $20 \mathrm{a}$ & $127 \mathrm{a}$ & $262 a$ & $72 \mathrm{a}$ & $261 b$ & $70 \mathrm{c}$ \\
\hline M6 & $56 \mathrm{a}$ & $19 a$ & $134 \mathrm{a}$ & $272 a$ & $70 \mathrm{a}$ & $326 a$ & $67 \mathrm{c}$ \\
\hline M7 & $57 \mathrm{a}$ & $20 \mathrm{a}$ & $128 \mathrm{a}$ & $258 \mathrm{a}$ & $72 a$ & $346 \mathrm{a}$ & $84 \mathrm{~b}$ \\
\hline \multicolumn{8}{|l|}{ Cultivares } \\
\hline BRS Pontal & $52 \mathrm{c}$ & $19 b$ & $111 \mathrm{~b}$ & $210 c$ & $64 a$ & $284 b$ & $85 a$ \\
\hline BRS Grafite & $58 \mathrm{~b}$ & $21 \mathrm{a}$ & $117 \mathrm{~b}$ & $245 b$ & $65 a$ & $326 a$ & $76 b$ \\
\hline BRS Radiante & $61 \mathrm{a}$ & $22 \mathrm{a}$ & $133 a$ & $278 \mathrm{a}$ & $67 \mathrm{a}$ & - & $68 \mathrm{c}$ \\
\hline Jalo Precoce & $54 \mathrm{c}$ & $18 \mathrm{~b}$ & $134 \mathrm{a}$ & $253 b$ & $69 a$ & - & $64 c$ \\
\hline Média & 56 & 20 & 124 & 247 & 66 & 305 & 73 \\
\hline $\mathrm{CV}(\%)$ & 12,6 & 14,4 & 17,9 & 19,2 & 21,4 & 18,0 & 13,6 \\
\hline
\end{tabular}

${ }^{(1)}$ Médias seguidas por letras iguais, nas colunas, não diferem entre si pelo teste de Scott-Knott, a 5\% de probabilidade; DAE: dias após a emergência. (2) M1, sem N; M2, todo o $\mathrm{N}$ incorporado ao solo, nas entrelinhas, aos $15 \mathrm{DAE}$; M3, todo o N a lanço, em cobertura, aos $15 \mathrm{DAE}$; M4, todo o N incorporado ao solo, no sentido transversal às linhas de semeadura; M5, todo o $\mathrm{N}$ incorporado com grade, antes da semeadura; M6, metade do $\mathrm{N}$ aplicado no sulco de semeadura, e o restante incorporado ao solo, nas entrelinhas, aos $15 \mathrm{DAE}$; M7, todo o N incorporado ao solo, nas entrelinhas, por ocasião da semeadura. 
acumulação de N pela cultivar BRS Grafite ocorreu quando todo $\mathrm{N}$ foi incorporado ao solo, na semeadura (M4 e M7), o que repetiu os resultados apresentados aos 62 DAE.

Durante todo o ciclo, a cultivar BRS Pontal, de porte semi-ereto e tipo II/III, teve a menor massa de MSPA (Tabela 2). Na fase inicial de desenvolvimento, as cultivares precoces, em especial a cultivar BRS Radiante, foram mais competitivas que as de ciclo médio, pois nas condições climáticas predominantes nas várzeas tropicais ocorrem mudanças morfológicas importantes, que favorecem o rápido crescimento do feijoeiro, e reduzem-lhe o ciclo (Didonet et al., 2002).

Em 2005, embora o estande final de algumas cultivares tenha diferido (Tabela 4), não se pode atribuir essas diferenças ao $\mathrm{N}$, pois seus efeitos sobre a emergência das plântulas dessas cultivares foram inconsistentes. A produtividade de grãos, os seus

Tabela 3. Desdobramento da interação entre manejo de nitrogênio e cultivar, na acumulação de nitrogênio e na massa da matéria seca da parte aérea (MSPA) do feijoeiro em várzea, em 2005(1).

\begin{tabular}{|c|c|c|c|c|c|}
\hline $\begin{array}{c}\text { Manejo } \\
\text { de } \\
\mathrm{N}^{(2)}\end{array}$ & $\begin{array}{c}\text { Acumulação de } \mathrm{N} \\
\begin{array}{c}28 \mathrm{DAE} \\
\left(\mathrm{kg} \mathrm{ha}^{-1}\right)\end{array}\end{array}$ & $\begin{array}{l}\text { MSPA } \\
62 \text { DAE } \\
\left(\mathrm{g} \mathrm{m}^{-2}\right)\end{array}$ & $\begin{array}{c}\text { Acumulação de } \mathrm{N} \\
\text { 62 DAE } \\
\left(\mathrm{kg} \mathrm{ha}^{-1}\right)\end{array}$ & $\begin{array}{c}\text { Acumulação de } \mathrm{N} \\
\begin{array}{c}67 \text { DAE } \\
\left(\mathrm{kg} \mathrm{ha}^{-1}\right)\end{array}\end{array}$ & $\begin{array}{c}\text { Acumulação de } \mathrm{N} \text { na parte aérea } \\
\text { e nos grãos } \\
\left(\mathrm{kg} \mathrm{ha}^{-1}\right)\end{array}$ \\
\hline \multicolumn{6}{|c|}{ BRS Pontal } \\
\hline M1 & $25 \mathrm{~b}$ & $337 \mathrm{c}$ & $58 \mathrm{c}$ & $18 \mathrm{~b}$ & $52 c$ \\
\hline M2 & $46 a$ & $591 \mathrm{a}$ & $143 a$ & $42 a$ & $110 \mathrm{a}$ \\
\hline M3 & $44 a$ & $574 a$ & $120 \mathrm{~b}$ & $42 a$ & $107 a$ \\
\hline M4 & $32 b$ & $526 \mathrm{a}$ & $132 a$ & $32 a$ & $120 \mathrm{a}$ \\
\hline M5 & $42 a$ & $454 \mathrm{~b}$ & $103 b$ & $27 \mathrm{~b}$ & $90 \mathrm{~b}$ \\
\hline M6 & $46 a$ & $591 \mathrm{a}$ & $145 a$ & $36 a$ & $97 \mathrm{~b}$ \\
\hline M7 & $39 a$ & $545 \mathrm{a}$ & $133 \mathrm{a}$ & $36 \mathrm{a}$ & $103 \mathrm{~b}$ \\
\hline Média & 39 & 517 & 119 & 33 & 88 \\
\hline \multicolumn{6}{|c|}{ BRS Grafite } \\
\hline M1 & $24 \mathrm{~b}$ & $294 c$ & $57 \mathrm{c}$ & $35 \mathrm{~b}$ & $42 c$ \\
\hline M2 & $36 a$ & $482 b$ & $96 \mathrm{~b}$ & $34 \mathrm{~b}$ & $99 a$ \\
\hline M3 & $41 \mathrm{a}$ & $554 \mathrm{a}$ & $111 b$ & $37 \mathrm{~b}$ & $91 b$ \\
\hline M4 & $38 \mathrm{a}$ & $620 \mathrm{a}$ & $147 \mathrm{a}$ & $55 \mathrm{a}$ & $111 \mathrm{a}$ \\
\hline M5 & $34 \mathrm{a}$ & $571 \mathrm{a}$ & $112 b$ & $33 b$ & $80 \mathrm{~b}$ \\
\hline M6 & $37 \mathrm{a}$ & $459 b$ & $92 b$ & $43 b$ & $81 \mathrm{~b}$ \\
\hline M7 & $37 \mathrm{a}$ & $648 \mathrm{a}$ & $156 \mathrm{a}$ & $55 \mathrm{a}$ & $107 \mathrm{a}$ \\
\hline Média & 35 & 518 & 110 & 42 & 80 \\
\hline \multicolumn{6}{|c|}{ BRS Radiante } \\
\hline M1 & $25 \mathrm{~b}$ & $188 \mathrm{a}$ & $11 \mathrm{a}$ & - & $41 d$ \\
\hline M2 & $36 a$ & $197 \mathrm{a}$ & $15 \mathrm{a}$ & - & $88 \mathrm{a}$ \\
\hline M3 & $31 \mathrm{~b}$ & $267 \mathrm{a}$ & $21 \mathrm{a}$ & - & $61 \mathrm{c}$ \\
\hline M4 & $49 a$ & $291 \mathrm{a}$ & $29 a$ & - & $84 a$ \\
\hline M5 & $41 \mathrm{a}$ & $205 a$ & $13 a$ & - & $70 \mathrm{~b}$ \\
\hline M6 & $40 \mathrm{a}$ & $194 a$ & $13 a$ & - & $58 \mathrm{c}$ \\
\hline M7 & $36 a$ & $197 \mathrm{a}$ & $20 \mathrm{a}$ & - & $85 a$ \\
\hline Média & 37 & 220 & 17 & - & 69 \\
\hline \multicolumn{6}{|c|}{ Jalo Precoce } \\
\hline M1 & $25 \mathrm{c}$ & $151 \mathrm{a}$ & $11 \mathrm{a}$ & - & $42 \mathrm{~d}$ \\
\hline M2 & $40 \mathrm{~b}$ & $187 \mathrm{a}$ & $13 a$ & - & $72 b$ \\
\hline M3 & $37 b$ & $221 \mathrm{a}$ & $17 \mathrm{a}$ & - & $60 \mathrm{c}$ \\
\hline M4 & $41 \mathrm{~b}$ & $234 \mathrm{a}$ & $19 a$ & - & $90 \mathrm{a}$ \\
\hline M5 & $39 b$ & $193 a$ & $14 a$ & - & $65 c$ \\
\hline M6 & $52 \mathrm{a}$ & $201 \mathrm{a}$ & $14 a$ & - & $58 \mathrm{c}$ \\
\hline M7 & $40 \mathrm{~b}$ & $213 a$ & $15 \mathrm{a}$ & - & $73 b$ \\
\hline Média & 39 & 200 & 15 & & 66 \\
\hline CV (\%) & 19,3 & 19,0 & 25,5 & 24,5 & 12,6 \\
\hline
\end{tabular}

${ }^{(1)}$ Médias seguidas por letras iguais, nas colunas, não diferem entre si pelo teste de Scott-Knott, a 5\% de probabilidade. (2)M1, sem N; M2, todo o N incorporado ao solo, nas entrelinhas, aos $15 \mathrm{DAE}$; M3, todo o $\mathrm{N}$ a lanço, em cobertura, aos $15 \mathrm{DAE}$; M4, todo o $\mathrm{N}$ incorporado ao solo, no sentido transversal às linhas de semeadura; M5, todo o $\mathrm{N}$ incorporado com grade, antes da semeadura; M6, metade do $\mathrm{N}$ aplicado no sulco de semeadura, e o restante incorporado ao solo, nas entrelinhas, aos $15 \mathrm{DAE}$; M7, todo o $\mathrm{N}$ incorporado ao solo, nas entrelinhas, por ocasião da semeadura. 
componentes e a produtividade biológica foram influenciados, significativamente, pela interação entre cultivar e manejo de N (Tabela 4). Como era esperado, o tratamento sem $\mathrm{N}$ proporcionou a menor produtividade

Tabela 4. Desdobramento da interação entre manejo de nitrogênio e cultivar, na produtividade de grãos e seus componentes, no feijoeiro em várzea, em $2005^{(1)}$.

\begin{tabular}{|c|c|c|c|c|c|c|}
\hline $\begin{array}{l}\text { Manejo } \\
\text { de } \mathrm{N}^{(2)}\end{array}$ & $\begin{array}{c}\text { Plantas } \\
\left(\mathrm{n}^{\mathrm{o}} \text { por } \mathrm{m}^{2}\right)\end{array}$ & $\begin{array}{c}\text { Vagem } \\
\left(\mathrm{n}^{\mathrm{o}} \text { por planta) }\right.\end{array}$ & $\begin{array}{c}\text { Grãos } \\
\left(\mathrm{n}^{\mathrm{o}} \text { por vagem }\right)\end{array}$ & $\begin{array}{c}\text { Massa de } \\
100 \text { grãos }(\mathrm{g})\end{array}$ & $\begin{array}{l}\text { Produtividade biológica } \\
\left(\mathrm{kg} \mathrm{ha}^{-1}\right)\end{array}$ & $\begin{array}{l}\text { Produtividade de grãos } \\
\qquad\left(\mathrm{kg} \mathrm{ha}^{-1}\right)\end{array}$ \\
\hline \multicolumn{7}{|c|}{ BRS Pontal } \\
\hline M1 & $23,6 \mathrm{a}$ & $6,5 c$ & $4,5 b$ & $21,0 \mathrm{c}$ & $4.798 c$ & $1.461 \mathrm{c}$ \\
\hline M2 & $22,5 \mathrm{a}$ & $10,2 \mathrm{a}$ & $5,5 \mathrm{a}$ & $23,9 \mathrm{a}$ & $10.338 \mathrm{a}$ & $2.969 \mathrm{a}$ \\
\hline M3 & $21,7 \mathrm{a}$ & $10,7 \mathrm{a}$ & $5,7 \mathrm{a}$ & $22,8 b$ & $9.878 \mathrm{a}$ & $3.026 \mathrm{a}$ \\
\hline M4 & $25,5 \mathrm{a}$ & $8,8 \mathrm{~b}$ & $5,9 a$ & $24,3 \mathrm{a}$ & $9.201 \mathrm{a}$ & $3.241 \mathrm{a}$ \\
\hline M5 & $23,9 a$ & $9,4 a$ & $5,4 \mathrm{a}$ & $22,0 \mathrm{~b}$ & $7.569 \mathrm{~b}$ & $2.675 \mathrm{~b}$ \\
\hline M6 & $25,4 a$ & $8,0 \mathrm{~b}$ & $5,6 \mathrm{a}$ & $22,1 b$ & $10.004 \mathrm{a}$ & $2.503 \mathrm{~b}$ \\
\hline Média & 24,1 & 8,8 & 5,4 & 23,0 & 8.695 & 2.706 \\
\hline \multicolumn{7}{|c|}{ Pérola } \\
\hline M1 & $18,5 \mathrm{a}$ & $10,4 \mathrm{a}$ & $4,3 \mathrm{c}$ & $23,1 \mathrm{c}$ & $7.208 b$ & $1.914 \mathrm{~d}$ \\
\hline M2 & $22,2 \mathrm{a}$ & $10,8 \mathrm{a}$ & $4,7 b$ & $24,8 \mathrm{~b}$ & $8.710 \mathrm{~b}$ & $2.836 \mathrm{~b}$ \\
\hline M3 & $21,4 \mathrm{a}$ & $10,3 a$ & $3,9 \mathrm{c}$ & $26,9 a$ & $9.511 \mathrm{a}$ & $2.329 \mathrm{c}$ \\
\hline M4 & $22,7 \mathrm{a}$ & $11,3 a$ & $5,6 \mathrm{a}$ & $24,2 b$ & $10.066 \mathrm{a}$ & $3.505 \mathrm{a}$ \\
\hline M5 & $24,5 \mathrm{a}$ & $9,6 \mathrm{a}$ & $4,7 b$ & $24,9 b$ & $7.976 b$ & $2.599 \mathrm{c}$ \\
\hline M6 & $22,0 \mathrm{a}$ & $10,0 \mathrm{a}$ & $4,5 b$ & $23,8 \mathrm{c}$ & $10.156 \mathrm{a}$ & $2.352 \mathrm{c}$ \\
\hline Média & 21,9 & 10,4 & 4,6 & 24,8 & 9.208 & 2.632 \\
\hline \multicolumn{7}{|c|}{ BRS Valente } \\
\hline M1 & $26,6 b$ & $7,6 \mathrm{~b}$ & $5,2 \mathrm{~b}$ & $17,4 \mathrm{c}$ & $5.191 \mathrm{c}$ & $1.874 \mathrm{~d}$ \\
\hline M2 & $30,1 \mathrm{a}$ & $8,3 \mathrm{~b}$ & $5,5 b$ & $19,6 \mathrm{~b}$ & $8.453 b$ & $2.898 b$ \\
\hline M3 & $22,6 \mathrm{c}$ & $10,0 \mathrm{a}$ & $6,1 \mathrm{a}$ & $19,5 b$ & $10.879 \mathrm{a}$ & $2.607 \mathrm{~b}$ \\
\hline M4 & $25,1 b$ & $11,0 \mathrm{a}$ & $5,7 b$ & $20,4 \mathrm{a}$ & $9.743 \mathrm{a}$ & $3.235 \mathrm{a}$ \\
\hline M5 & $26,8 b$ & $8,6 b$ & $5,4 b$ & $19,4 b$ & $8.690 \mathrm{~b}$ & $2.428 \mathrm{c}$ \\
\hline M6 & $23,3 \mathrm{c}$ & $10,3 \mathrm{a}$ & $5,5 b$ & $17,0 \mathrm{c}$ & $8.734 b$ & $2.258 \mathrm{c}$ \\
\hline M7 & $29,7 \mathrm{a}$ & $8,0 \mathrm{~b}$ & $5,6 \mathrm{~b}$ & $21,0 \mathrm{a}$ & $9.597 \mathrm{a}$ & $2.816 \mathrm{~b}$ \\
\hline Média & 26,6 & 9,1 & 5,6 & 19,2 & 8.755 & 2.588 \\
\hline \multicolumn{7}{|c|}{ BRS Grafite } \\
\hline M1 & $25,1 d$ & $6,9 a$ & $3,9 b$ & $19,2 \mathrm{c}$ & $4.653 c$ & $1.254 \mathrm{c}$ \\
\hline M2 & $36,3 a$ & $6,8 \mathrm{a}$ & $4,9 \mathrm{a}$ & $23,0 \mathrm{~b}$ & $7.785 b$ & $2.817 \mathrm{a}$ \\
\hline M3 & $28,6 \mathrm{c}$ & $7,6 \mathrm{a}$ & $4,6 \mathrm{a}$ & $22,1 b$ & $8.218 b$ & $2.220 \mathrm{~b}$ \\
\hline M4 & $27,9 \mathrm{c}$ & $7,9 \mathrm{a}$ & $4,7 \mathrm{a}$ & $25,6 \mathrm{a}$ & $9.961 \mathrm{a}$ & $2.731 \mathrm{a}$ \\
\hline M5 & $29,3 \mathrm{c}$ & $7,9 \mathrm{a}$ & $4,3 b$ & $21,5 b$ & $8.237 b$ & $2.155 b$ \\
\hline M6 & $32,0 \mathrm{~b}$ & $6,6 a$ & $4,9 \mathrm{a}$ & $21,9 b$ & $7.036 \mathrm{~b}$ & $2.296 b$ \\
\hline \multicolumn{7}{|c|}{ BRS Radiante } \\
\hline M1 & $25,2 b$ & $5,7 \mathrm{a}$ & $3,3 \mathrm{a}$ & $28,7 \mathrm{e}$ & $3.850 \mathrm{~b}$ & $1.359 \mathrm{~d}$ \\
\hline M2 & $29,4 \mathrm{a}$ & $6,9 a$ & $3,8 \mathrm{a}$ & $37,4 b$ & $5.069 \mathrm{~b}$ & $2.913 a$ \\
\hline M3 & $22,4 b$ & $7,6 \mathrm{a}$ & $3,6 a$ & $33,8 \mathrm{c}$ & $6.550 \mathrm{a}$ & $2.121 \mathrm{c}$ \\
\hline M4 & $23,7 b$ & $7,3 \mathrm{a}$ & $3,9 a$ & $39,0 \mathrm{a}$ & $6.601 \mathrm{a}$ & $2.678 \mathrm{a}$ \\
\hline M5 & $23,1 b$ & $8,3 a$ & $3,7 \mathrm{a}$ & $33,5 \mathrm{c}$ & $4.766 \mathrm{~b}$ & $2.403 b$ \\
\hline M6 & $27,2 \mathrm{a}$ & $6,6 a$ & $3,5 \mathrm{a}$ & $31,9 d$ & $4.433 b$ & $2.012 \mathrm{c}$ \\
\hline M7 & $27,5 \mathrm{a}$ & $7,2 \mathrm{a}$ & $3,8 \mathrm{a}$ & $37,5 \mathrm{~b}$ & $4.729 b$ & $2.859 \mathrm{a}$ \\
\hline Média & 25,5 & 7,1 & 3,7 & 34,5 & 5.143 & 2.335 \\
\hline \multicolumn{7}{|c|}{ Jalo Precoce } \\
\hline M1 & $25,8 \mathrm{c}$ & $5,1 \mathrm{a}$ & $3,7 b$ & $29,8 \mathrm{e}$ & $3.476 \mathrm{a}$ & $1.463 \mathrm{c}$ \\
\hline M2 & $33,0 \mathrm{a}$ & $5,0 \mathrm{a}$ & $4,3 \mathrm{a}$ & $35,3 b$ & $4.515 a$ & $2.552 \mathrm{a}$ \\
\hline M3 & $28,4 b$ & $5,6 a$ & $4,1 \mathrm{a}$ & $33,1 \mathrm{c}$ & $5.333 \mathrm{a}$ & $2.169 b$ \\
\hline M4 & $24,0 \mathrm{c}$ & $6,6 a$ & $4,3 \mathrm{a}$ & $36,3 \mathrm{a}$ & $5.054 \mathrm{a}$ & $2.490 \mathrm{a}$ \\
\hline M5 & $27,8 b$ & $5,7 \mathrm{a}$ & $4,0 \mathrm{a}$ & $33,1 \mathrm{c}$ & $4.395 \mathrm{a}$ & $2.135 b$ \\
\hline M6 & $28,4 b$ & $5,9 a$ & $3,8 b$ & $31,3 \mathrm{~d}$ & $4.318 \mathrm{a}$ & $2.026 \mathrm{~b}$ \\
\hline M7 & $27,9 \mathrm{~b}$ & $5,9 \mathrm{a}$ & $4,3 \mathrm{a}$ & $35,1 \mathrm{~b}$ & $5.134 \mathrm{a}$ & $2.509 \mathrm{a}$ \\
\hline Média & 27,9 & 5,9 & 4,1 & 33,4 & 4.604 & 2.192 \\
\hline CV (\%) & 11,5 & 15,5 & 8,6 & 3,7 & 15,1 & 9,6 \\
\hline
\end{tabular}

${ }^{(1)}$ Médias seguidas por letras iguais, nas colunas, não diferem entre si pelo teste de Scott-Knott, a 5\% de probabilidade. ${ }^{(2)}$ M1, sem N; M2, todo o N incorporado ao solo nas entrelinhas aos $15 \mathrm{DAE}$; M3, todo o $\mathrm{N}$ a lanço, em cobertura, aos $15 \mathrm{DAE}$; M4, todo o $\mathrm{N}$ incorporado ao solo no sentido transversal às linhas de semeadura; M5, todo o $\mathrm{N}$ incorporado com grade antes da semeadura; M6, metade do N aplicado no sulco de semeadura, e o restante incorporado ao solo nas entrelinhas, aos $15 \mathrm{DAE}$; M7, todo o $\mathrm{N}$ incorporado ao solo nas entrelinhas, por ocasião da semeadura. 
biológica e, assim como no primeiro ano, menor produtividade de grãos, em todas as cultivares, o que foi refletido pelos menores valores observados nos componentes de produção, principalmente na massa de 100 grãos, mesmo considerando-se que as várzeas constituem áreas férteis para a produção das culturas (Santos \& Silveira, 1996). Em geral, as aplicações totais de $\mathrm{N}$, aplicado em sulcos distintos das linhas de semeadura, por ocasião dessa (M4 e M7), ou aos 15 DAE (M2), resultaram em maiores fitomassas e maior produtividade de grãos, do que as aplicações de todo o $\mathrm{N}$ incorporado com grade antes da semeadura (M5), a lanço em cobertura (M3), ou incorporado em parte aos 15 DAE (M6). Ao avaliar a eficiência de fontes e época de aplicação de N, Kluthcouscki et al. (2004) obtiveram melhores respostas da cultivar Carioca, em várzeas tropicais, quando o $\mathrm{N}$ foi aplicado por ocasião da semeadura e aos dez DAE. Verificaram, também, que a aplicação de $90 \mathrm{~kg} \mathrm{ha}^{-1}$ de $\mathrm{N}$, incorporados ao solo no sentido transversal às linhas de semeadura, proporcionou a maior produtividade de grãos. A incorporação do fertilizante nitrogenado nas entrelinhas, simultaneamente à semeadura, é mais vantajosa, em razão da redução de uma operação de adubação. Com isso, procura-se evitar a entrada, na lavoura, de máquinas e equipamentos que danificam as plantas.

Na aplicação a lanço em cobertura (M3), pode ter ocorrido maior perda de $\mathrm{N}$ por volatilização, pois no cultivo de espécies de sequeiro em várzeas, na entressafra do arroz irrigado, o fornecimento de água às plantas se dá por subirrigação, a qual favorece a formação de uma fina camada seca na superfície do solo que pode impossibilitar ou retardar a absorção do N pelo feijoeiro. Segundo Silva et al. (2002), o atraso no fornecimento de $\mathrm{N}$ ao feijoeiro reduz a produtividade de grãos, provavelmente decorrente da imobilização biológica do $\mathrm{N}$ do solo. A incorporação de todo o $\mathrm{N}$, com grade, antes da semeadura (M5) também pode favorecer a sua perda em razão do maior contato do fertilizante com as partículas de solo.

A eficiência do uso de $\mathrm{N}$ variou com as cultivares BRS Pontal, BRS Grafite, BRS Radiante, Jalo Precoce e com o tipo de eficiência calculada (Tabela 5). As eficiências agronômica (EA), de recuperação (ER) e a de utilização (EU) de N, pelas quatro cultivares, diferiram significativamente com os manejos do fertilizante, enquanto a eficiência fisiológica (EF), exceto pela cultivar BRS Radiante, e a agrofisiológica (EAF), exceto pela cultivar BRS Pontal, não diferiram. A incorporação de todo o $\mathrm{N}$, por ocasião da semeadura (M4 e M7) e aos 15 DAE (M2), propiciaram as maiores EA.

Tabela 5. Efeitos do manejo de nitrogênio, na eficiência de uso do nutriente, em cultivares de feijoeiro em várzea, em $2005^{(1)}$.

\begin{tabular}{|c|c|c|c|c|c|}
\hline \multirow{2}{*}{$\begin{array}{l}\text { Manejo } \\
\text { de } \mathrm{N}^{(2)}\end{array}$} & \multicolumn{5}{|c|}{ Eficiência de uso de $\mathrm{N}^{(3)}$} \\
\hline & $\begin{array}{c}\text { EA } \\
\left(\mathrm{kg} \mathrm{kg}^{-1}\right)\end{array}$ & $\begin{array}{c}\mathrm{EF} \\
\left(\mathrm{kg} \mathrm{kg}^{-1}\right)\end{array}$ & $\begin{array}{c}\text { EAF } \\
\left(\mathrm{kg} \mathrm{kg}^{-1}\right)\end{array}$ & $\begin{array}{l}\text { ER } \\
(\%)\end{array}$ & $\begin{array}{c}\mathrm{EU} \\
\left(\mathrm{kg} \mathrm{kg}^{-1}\right)\end{array}$ \\
\hline \multicolumn{6}{|c|}{ BRS Pontal } \\
\hline M1 & - & - & - & - & - \\
\hline M2 & $17 \mathrm{a}$ & $108 \mathrm{a}$ & $28 \mathrm{~b}$ & $33 b$ & $62 \mathrm{a}$ \\
\hline M3 & $17 \mathrm{a}$ & $99 a$ & $30 \mathrm{~b}$ & $20 \mathrm{~b}$ & $57 \mathrm{a}$ \\
\hline M4 & $20 \mathrm{a}$ & $71 \mathrm{a}$ & $31 \mathrm{~b}$ & $54 \mathrm{a}$ & $49 a$ \\
\hline M5 & $14 \mathrm{~b}$ & $119 \mathrm{a}$ & $52 \mathrm{a}$ & $25 b$ & $31 \mathrm{~b}$ \\
\hline M6 & $12 b$ & $145 \mathrm{a}$ & $29 \mathrm{~b}$ & $18 \mathrm{~b}$ & $58 \mathrm{a}$ \\
\hline M7 & $18 \mathrm{a}$ & $96 a$ & $37 \mathrm{~b}$ & $35 \mathrm{~b}$ & $48 \mathrm{a}$ \\
\hline Média & 16 & 106 & 34 & 52 & 51 \\
\hline \multicolumn{6}{|c|}{ BRS Grafite } \\
\hline M1 & - & - & - & - & - \\
\hline M2 & $17 \mathrm{a}$ & $61 \mathrm{a}$ & $31 \mathrm{a}$ & $59 a$ & $35 \mathrm{~b}$ \\
\hline M3 & $11 \mathrm{~b}$ & $80 a$ & $26 a$ & $49 b$ & $40 \mathrm{~b}$ \\
\hline M4 & $16 \mathrm{a}$ & $86 a$ & $26 a$ & $70 \mathrm{a}$ & $59 a$ \\
\hline M5 & $10 \mathrm{~b}$ & $118 \mathrm{a}$ & $30 a$ & $36 \mathrm{~b}$ & $40 \mathrm{~b}$ \\
\hline M6 & $12 b$ & $68 \mathrm{a}$ & $31 \mathrm{a}$ & $40 \mathrm{~b}$ & $27 b$ \\
\hline M7 & $18 \mathrm{a}$ & $97 \mathrm{a}$ & $31 \mathrm{a}$ & $64 a$ & $61 \mathrm{a}$ \\
\hline Média & 15 & 85 & 29 & 53 & 43 \\
\hline \multicolumn{6}{|c|}{ BRS Radiante } \\
\hline M1 & - & - & - & - & - \\
\hline M2 & $17 \mathrm{a}$ & $26 \mathrm{~b}$ & $32 a$ & $52 \mathrm{a}$ & $14 \mathrm{~b}$ \\
\hline M3 & $9 \mathrm{c}$ & $123 a$ & $35 \mathrm{a}$ & $22 b$ & $30 a$ \\
\hline M4 & $15 \mathrm{a}$ & $65 \mathrm{~b}$ & $34 a$ & $47 \mathrm{a}$ & $31 \mathrm{a}$ \\
\hline M5 & $12 b$ & $29 \mathrm{~b}$ & $35 \mathrm{a}$ & $32 b$ & $10 \mathrm{~b}$ \\
\hline M6 & $7 \mathrm{c}$ & $37 b$ & $38 \mathrm{a}$ & $18 \mathrm{~b}$ & $7 b$ \\
\hline M7 & $17 \mathrm{a}$ & $20 \mathrm{~b}$ & $33 a$ & $49 \mathrm{a}$ & $10 \mathrm{~b}$ \\
\hline Média & 12 & 50 & 34 & 37 & 17 \\
\hline \multicolumn{6}{|c|}{ Jalo Precoce } \\
\hline M1 & - & - & - & - & - \\
\hline M2 & $12 \mathrm{a}$ & $34 a$ & $34 a$ & $33 b$ & $12 a$ \\
\hline M3 & $8 \mathrm{~b}$ & $102 a$ & $40 \mathrm{a}$ & $20 \mathrm{~b}$ & $21 \mathrm{a}$ \\
\hline M4 & $11 \mathrm{a}$ & $39 a$ & $25 \mathrm{a}$ & $54 \mathrm{a}$ & $18 \mathrm{a}$ \\
\hline M5 & $8 \mathrm{~b}$ & $63 a$ & $39 a$ & $25 b$ & $11 \mathrm{a}$ \\
\hline M6 & $6 \mathrm{~b}$ & $64 \mathrm{a}$ & $33 a$ & $18 \mathrm{~b}$ & $9 a$ \\
\hline M7 & $12 \mathrm{a}$ & $53 a$ & $37 \mathrm{a}$ & $35 \mathrm{~b}$ & $18 \mathrm{a}$ \\
\hline Média & 10 & 59 & 35 & 31 & 15 \\
\hline $\mathrm{CV}(\%)$ & 20,3 & 46,2 & 23,8 & 26,5 & 36,2 \\
\hline
\end{tabular}

${ }^{(1)}$ Médias seguidas por letras iguais, nas colunas, não diferem entre si pelo teste de Scott-Knott, a 5\% de probabilidade. (2) M1, sem N; M2, todo o $\mathrm{N}$ incorporado ao solo nas entrelinhas, aos $15 \mathrm{DAE}$; M3, todo o $\mathrm{N}$ a lanço, em cobertura, aos $15 \mathrm{DAE}$; M4, todo o $\mathrm{N}$ incorporado ao solo no sentido transversal às linhas de semeadura; M5, todo o $\mathrm{N}$ incorporado com grade antes da semeadura; M6, metade do $\mathrm{N}$ aplicado no sulco de semeadura, e o restante incorporado ao solo nas entrelinhas, aos 15 DAE; $\mathrm{M} 7$, todo o $\mathrm{N}$ incorporado ao solo nas entrelinhas, por ocasião da semeadura. ${ }^{(3)}$ EA, eficiência agronômica; EF, eficiência fisiológica; EAF, eficiência agrofisiológica; ER, eficiência de recuperação; EU, eficiência de utilização. 
As cultivares BRS Pontal, BRS Grafite, BRS Radiante e Jalo Precoce produziram até 20, 18, 17 e $12 \mathrm{~kg}$ de grãos por quilograma de $\mathrm{N}$ aplicado, respectivamente.

A EF foi maior na cultivar BRS Pontal e menor na BRS Radiante que, com a aplicação de todo o $\mathrm{N}$, a lanço em cobertura (M3), produziu $123 \mathrm{~kg}$ de matéria seca (palha + grãos) por quilograma de $\mathrm{N}$ acumulado na parte aérea e grãos, e diferiu significativamente dos demais manejos. Na média, com a acumulação de $1 \mathrm{~kg}$ de $\mathrm{N}$ na parte aérea e grãos, foram produzidos 106, 85, 50 e $59 \mathrm{~kg}$ de matéria seca pelas cultivares BRS Pontal, BRS Grafite, BRS Radiante e Jalo Precoce, respectivamente.

Os manejos de $\mathrm{N}$ influenciaram significativamente a EAF apenas na cultivar BRS Pontal, e houve variação de 28 a $52 \mathrm{~kg}$ de grãos produzidos por quilograma de $\mathrm{N}$ acumulado na parte aérea e grãos. Na média, com a acumulação de $1 \mathrm{~kg}$ de $\mathrm{N}$ pela planta, foram produzidos 34, 29, 34 e $35 \mathrm{~kg}$ de grãos pelas cultivares BRS Pontal, BRS Grafite, BRS Radiante e Jalo Precoce, respectivamente.

A ER de $\mathrm{N}$ foi influenciada pelos manejos do fertilizante, tendo-se obtido os maiores porcentuais com a incorporação de todo o $\mathrm{N}$, por ocasião da semeadura (M4 e M7) e aos 15 DAE (M2), o que significa que nos demais tratamentos grande parte do $\mathrm{N}$ foi perdida, e isto indica se tratar de manejos que favorecem a perda de $\mathrm{N}$ em várzea. Em média, as cultivares BRS Pontal, BRS Grafite, BRS Radiante e Jalo Precoce tiveram ER de 52, 53, 37 e 31\%, respectivamente. Isso significa que, em várzea, a perda de $\mathrm{N}$ nas cultivares de ciclo médio foi ao redor de $47 \%$ e, nas precoces, $66 \%$.

Exceto na cultivar Jalo Precoce, a EU de N pelas cultivares foi influenciada significativamente pelos manejos de N. Na cultivar BRS Pontal, a incorporação do fertilizante com grade, antes da semeadura (M5), apresentou EU significativamente menor que nas demais. Na cultivar BRS Grafite, a incorporação de todo o $\mathrm{N}$ ao solo, por ocasião da semeadura (M4 e M7), proporcionou maiores EU. $\mathrm{Na}$ cultivar BRS Radiante, os tratamentos com todo o $\mathrm{N}$ incorporado ao solo na semeadura (M4) ou aplicado a lanço em cobertura aos 15 DAE (M3) proporcionaram os maiores valores de EU. Na média, as cultivares BRS Pontal, BRS Grafite, BRS Radiante e Jalo Precoce produziram 51, 43, 17 e $15 \mathrm{~kg}$ de fitomassa por quilograma de $\mathrm{N}$ recuperado, respectivamente, o que indica que existe grande potencial de aumento da produtividade de grãos de feijão, com a seleção de genótipos mais eficientes na absorção e utilização de $\mathrm{N}$.

A produção e distribuição de fotoassimilados estão relacionadas com o suprimento de $\mathrm{N}$ e com a cultivar. As cultivares que respondem mais à adubação nitrogenada são, em geral, mais eficientes em fotossíntese (Osada, 1995). Com o intuito de identificar linhagens de feijoeiro com maior tolerância ao estresse de $\mathrm{N}$ e com maior resposta ao nutriente aplicado em cobertura, Furtini et al. (2006) verificaram que apenas 22 linhagens, das 100 testadas, responderam positivamente à adubação com $40 \mathrm{~kg} \mathrm{ha}^{-1} \mathrm{de} \mathrm{N}$ e, entre elas, a EU variou de 11,3 a $18,3 \mathrm{~kg}$ de grãos por quilograma de $\mathrm{N}$ aplicado. Em várzea, Santos \& Fageria (2005) verificaram que, com a aplicação de $1 \mathrm{~kg}$ de N, foram produzidos $16 \mathrm{~kg}$ de grãos de feijão pela cultivar Pérola; com a absorção de $1 \mathrm{~kg}$ de $\mathrm{N}$, foram produzidos $81 \mathrm{~kg}$ de MSPA, e a EAF foi de $23 \mathrm{~kg}$ de grãos produzidos por quilograma de $\mathrm{N}$ acumulado na palha $\mathrm{e}$ nos grãos.

Fageria \& Stone (2003) relatam que a deficiência de $\mathrm{N}$ nas culturas é a mais freqüente e está relacionada com a elevada acidez dos solos de várzeas, além das baixas doses de aplicação e diminuição do teor de matéria orgânica, em razão de cultivos sucessivos. Kluthcouski et al. (2004) mencionam que a principal causa da menor disponibilidade de $\mathrm{N}$ em várzeas é a imobilização microbiana do fertilizante nitrogenado. A magnitude em que a imobilização do $\mathrm{N}$ mineral afeta a sua disponibilidade, para a cultura subseqüente, depende da relação $\mathrm{C} / \mathrm{N}$, composição e quantidade de resíduos produzidos pela cultura anterior (Fageria \& Stone, 2003). Com isso, a elevada exigência de $\mathrm{N}$ pelo feijoeiro, observada nos estudos em várzeas, possivelmente se deveu ao grande volume de resíduos deixados na superfície do solo, pela cultura do arroz irrigado.

As EA, ER e EU tiveram associação positiva com a produtividade de grãos e essas relações foram lineares (Figura 2). O aumento de uma unidade de EA, ER e EU correspondeu a aumentos de 87, 17 e $10 \mathrm{~kg} \mathrm{ha}^{-1}$ de grãos de feijão, respectivamente. Santos \& Fageria (2005) também obtiveram associação positiva da EA com a produtividade de grãos de feijão. $\mathrm{O} N$ é um dos nutrientes mais limitantes para a produção das culturas e sua eficiência de uso é importante para a sustentabilidade econômica dos sistemas agrícolas (Fageria \& Baligar, 2005). 

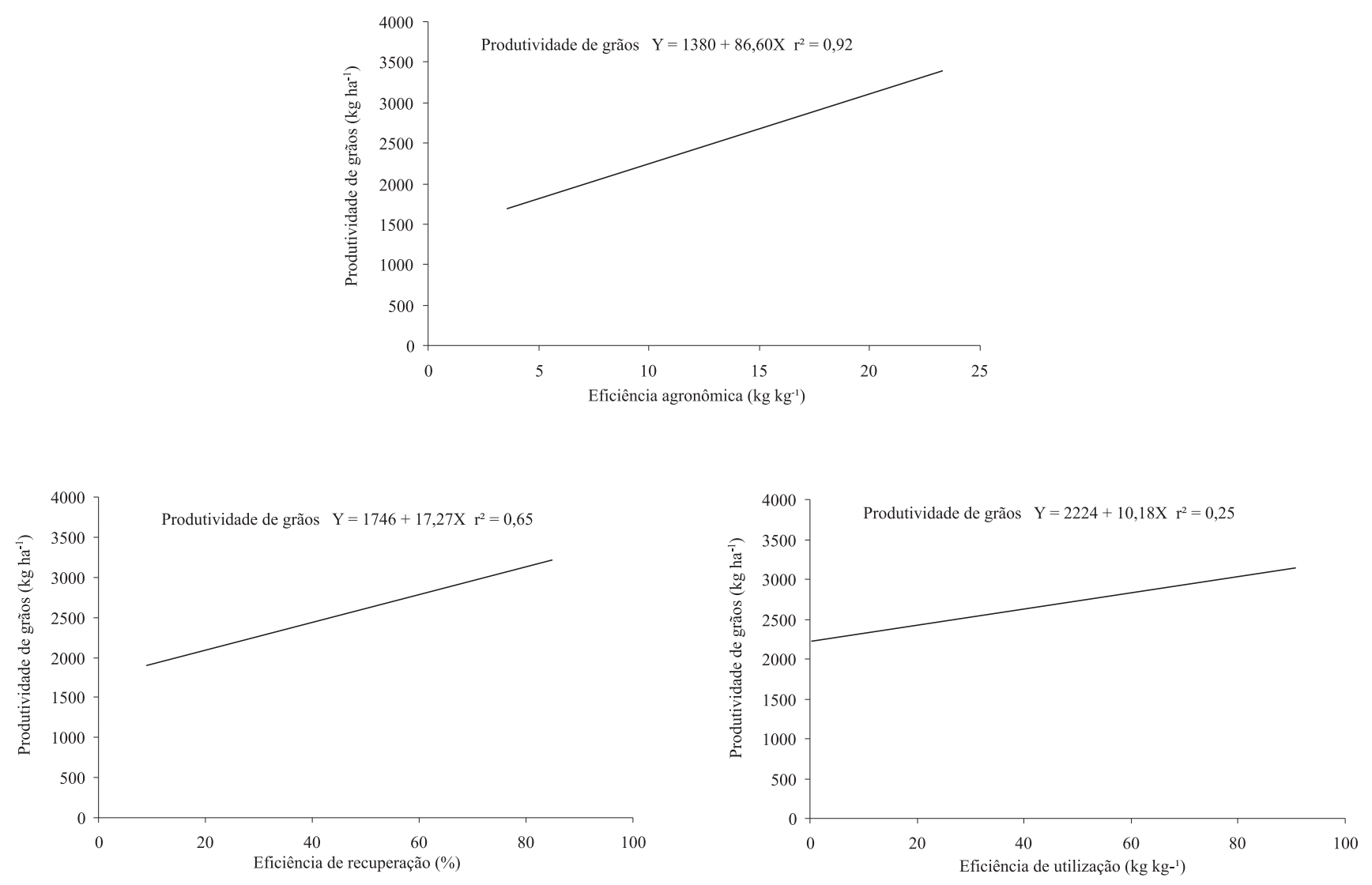

Figura 2. Relação entre a produtividade de grãos e as eficiências agronômica, de recuperação e de utilização de nitrogênio, de cultivares de feijoeiro em várzea, em 2005.

\section{Conclusões}

1. A produtividade de grãos e a eficiência de uso de nitrogênio pelas cultivares de feijoeiro diferem com o manejo do fertilizante nitrogenado.

2. A aplicação de nitrogênio no sulco de semeadura afeta a germinação das sementes e reduz a população de feijoeiros.

3. A incorporação de todo o nitrogênio em sulcos distintos das linhas da semeadura, por ocasião da semeadura ou até aos 15 dias após a emergência, é mais eficaz na produtividade de grãos de feijão do que a aplicação a lanço, na superfície, ou a incorporação com grade antes da semeadura.

4. A produtividade de grãos das cultivares de feijoeiro é associada positivamente com as eficiências agronômica, de recuperação e de utilização de nitrogênio.

5. A eficiência de uso de nitrogênio pelo feijoeiro é maior nas cultivares de ciclo médio do que nas precoces.

\section{Referências}

AIDAR, H.; KLUTHCOUSKI, J.; THUNG, M. Estabelecimento da cultura. In: AIDAR, H.; KLUTHCOUSKI, J.; STONE, L.F. (Ed.). Produção do feijoeiro comum em várzeas tropicais. Santo Antônio de Goiás: Embrapa Arroz e Feijão, 2002. p.105-119.

BERNARDO, S. Manual de irrigação. 7.ed. Viçosa: Imprensa Universitária, 2005, 611p.

BREDEMEIER, C.; MUNDSTOCK, C.M. Regulação da absorção e assimilação do nitrogênio nas plantas. Ciência Rural, v.30, p.365-372, 2000.

DIDONET, A.D.; AIDAR, H.; THUNG, M.; KLUTHCOUSKI, J.; SOARES, D.M. Efeitos da alta temperatura do ar. In: AIDAR, H.; KLUTHCOUSKI, J.; STONE, L.F. (Ed.). Produção do feijoeiro comum em várzeas tropicais. Santo Antônio de Goiás: Embrapa Arroz e Feijão, 2002. p.53-66.

FAGERIA, N.K.; BALIGAR, V.C. Enhancing nitrogen use efficiency in crop plants. Advances in Agronomy, v.88, p.97-185, 2005.

FAGERIA, N.K.; STONE, L.F. Manejo do nitrogênio. In: FAGERIA, N.K.; STONE, L.F.; SANTOS, A.B. dos. Manejo da fertilidade do solo para o arroz irrigado. Santo Antônio de Goiás: Embrapa Arroz e Feijão, 2003. p.51-94. 
FURTINI, I.V.; RAMALHO, M.A.P.; ABREU, A. de F.B.; FURTINI NETO, A.E.F. Resposta diferencial de linhagens de feijoeiro ao nitrogênio. Ciência Rural, v.36, p.1696-1700, 2006.

KLUTHCOUSKI, J.; AIDAR, H.; THUNG, M. Manejo do nitrogênio. In: AIDAR, H.; BIAVA, M. Produção de sementes sadias do feijão comum em várzeas tropicais. Santo Antônio de Goiás: Embrapa Arroz e Feijão; Campinas: Embrapa Informática Agropecuária, 2004. (Embrapa Arroz e Feijão. Sistemas de Produção, 4). Disponível em http://sistemaproducao.cnptia.embrapa.br/ FontesHTML/Feijao/FeijaoVarzeaTropical/manejo_nitrogenio.htm. Acesso em 5 jul. 2007.

OLIVEIRA, I.P. de; ARAUJO, R.S.; DUTRA, L.G. Nutrição mineral e fixação biológica de nitrogênio. In: ARAUJO, R.S.; RAVA, C.A.; STONE, L.F.; ZIMMERMANN, M.J. de O. (Coord.). Cultura do feijoeiro comum no Brasil. Piracicaba: Potafos, 1996. p.169-221.

OSADA, A. Photosynthesis and respiration in relation to nitrogen responsiveness. In: MATSUO, T.; KUMAZAWA, K.; ISHII, R.; ISHIHARA, K.; HIRATA, H. (Ed.). Science of the rice plant. Tokyo: Food and Agriculture Policy Research Center, 1995. v.2, p.696-703.

SANTOS, A.B. dos; FAGERIA, N.K. Eficiência de uso de nitrogênio em cobertura pelo feijoeiro em várzea tropical. In: CONGRESSO
NACIONAL DE PESQUISA DE FEIJÃO, 8., 2005, Goiânia. Anais. Santo Antônio de Goiás: Embrapa Arroz e Feijão, 2005. v.2. p.1007-1009.

SANTOS, A.B. dos; FAGERIA, N.K.; SILVA, O.F. da; MELO, M.L.B. de. Resposta do feijoeiro ao manejo de nitrogênio em várzeas tropicais. Pesquisa Agropecuária Brasileira, Brasília, v.38, p.12651271, 2003.

SANTOS, A.B. dos; SILVA, O.F. da. Manejo do nitrogênio. In: AIDAR, H.; KLUTHCOUSKI, J.; STONE, L.F. (Ed.). Produção do feijoeiro comum em várzeas tropicais. Santo Antônio de Goiás: Embrapa Arroz e Feijão, 2002. p.207-216.

SANTOS, A.B. dos; SILVEIRA, P.M. da. Cultivo em várzeas. In: ARAUJO, R.S.; RAVA, C.A.; STONE, L.F.; ZIMMERMANN, M.J. de O. (Coord.). Cultura do feijoeiro comum no Brasil. Piracicaba: Potafos, 1996. p.589-617.

SILVA, C.C. da; SILVEIRA, P.M. da. Influência de sistemas agrícolas na resposta do feijoeiro (Phaseolus vulgaris L.) irrigado à adubação nitrogenada em cobertura. Pesquisa Agropecuária Tropical, v.30, p.86-96, 2000.

SILVA, G.M.; STONE, L.F.; MOREIRA, J.A.A. Manejo da adubação nitrogenada no feijoeiro irrigado sob plantio direto. Pesquisa Agropecuária Tropical. v.32, p.1-5, 2002. 